\title{
Environmental ecosystem services assessment based on urban green infrastructure structure indicators with case study in Shanghai
}

\author{
Liang Zhao* \\ Shenzhen Institute, Chinese Academy of Urban Planning and Design, Shenzhen, Guangdong, 518040, China
}

\begin{abstract}
Urban green infrastructure (UGI) attracts much interest because they could provide urban ecosystem services (UES). Among all various methodologies, the UGI structure-based modelling is favored for advantages in physiological mechanisms. This work concerns on environmental services, including "air purification," "microclimate regulation," "noise reduction," "carbon sequestration and storage," and "rainwater retention." A new assessment methodology based on UGI structure indicator was constructed with nine UGI model structures and quantitative values. With implemented in two urban parks in Shanghai, this methodology is speculated to be suitable for patch-level cases, and can make certain efforts to regions without sufficient data.
\end{abstract}

\section{Introduction}

More than half of the world's population currently lives in urban areas, where growth of nearly all of future global population will take place; thus, urban areas will become the focus of future studies [1]. Environmental deterioration is a major challenge in urban areas, and being the main habitat supporting a dense population and intense human activities, urban ecosystems suffer from severe air and noise pollutions [2] and other environmental problems, including urban heating and flooding caused by global climate change [3]-[5].

However, urban regions are also considered crucial sites for human-environment sustainability [1]. Urban green infrastructure (UGI), which is variously labelled as urban green, urban plant, urban vegetation, etc. and which includes urban forests, parks, allotments, street trees, and green roofs [6], receives much attention because of its function in environment improvement [7]. Moreover, owing to the direct interactions with UGI and human activities [8], urban ecosystem services (UES) assessment has also become a major concern.

UES is basically classified into services including support, regulation, provisioning, and cultural services [9], and a standardized methodology in UES assessment remains lacking [10] because of the varying back-grounds of researchers [11].

It needs to focus on vegetation physiology because its influence and comprehensive effects in environment improving. For example, air purification is mechanically hinged on the plants' capacity in dust glutinousness, particulate absorption, material dissolution, etc., and all of these processes are physiologically controlled by the stomatal mechanism, cellular activity, and gaseous sensitivity, among others [12]. Thus, even without considering VOCs (volatile organic compounds; pollution emitted from vegetation itself), air purification function has been fully complicated because of comprehensive impacts with various factors of biotype, species, vegetation age, and vegetation-environment interactions.

The current methodologies being implemented largely neglect the factors contributed by physiological mechanisms but largely in socio-economical and spectrographic aspects. Monetary value assessment is more favoured and widely discussed instead. Thus, basic concerns in marketing and various sub-methodologies, house-hold production functions, and hedonic pricing have been analysed. However, all of those methodologies neglected physiological mechanisms, which were highly considered unstable because they strongly fluctuate in terms of market prices [11]. Moreover, GIS and remote sensing are widely implemented [13]; however, certain mismatching errors could not be avoided in UGI radiation and identification. Another disadvantage lies in the limited satellite images acquisition, and technical skills may restrict studies involving UES assessment analysis.

The UGI structure-based modelling has advantages in physiology connections and primary data acquisition [14] and is thus presented herein, and its indicators are considered as crucial factors. Basing on previous reports and local situations [15]-[17], we constructed the modelling methodology. First, the interconnections of UGI structures and specific UES were separately discussed based on literature review, aiming to select the crucial structural indicators. Second, we constructed the model UGI structures basing mainly on those indicators as well as on real situations under consideration, aiming to characterize the entire research site. Third, basing on the efforts those model structures contribute, we constructed an assessment system with quantitative values

${ }^{*}$ Corresponding author's e-mail: 494885966@qq.com 
(positive, neutral, and negative with grades presented). Finally, basing on those UES grades and related placebased data (also collected through field works), comprehensive analysis could be made on the entire research site using the results of both quantitative and qualitative assessments.

This work included two UGI sites in Shanghai, and basing on the results of the field survey conducted from September to December in 2014, we implemented our methodology and obtained quantitative results on UES of air purification, microclimate regulation, noise reduction, carbon sequestration and storage, and rainwater retention. In addition, we listed the advantages and limitations of our methodology based on our results.

\section{Methodology}

\subsection{Literature review on UGI structure indicators}

The UES for "air purification," "microclimate regulation," "noise reduction," "carbon sequestration and storage (CSS)," and "rainwater retention" are discussed in this section. In addition, the factors of "UGI structure indicators" were investigated.

\subsubsection{Air purification}

The literature review on the mechanism of air pollution revealed that, air pollutants are mainly removed through dry deposition [18]. Furthermore, gaseous and particulate pollutants are mainly transported into and absorbed by the plants through the leaves [19]. Thus, "leaf size" is the most affected structural factor [20]. A number of scholars investigated on the "biotype factor" and concluded that the capacity of trees is higher than that of bushes and herbs [21]. Another important vegetation factor is the "coniferous or deciduous." Deciduous species exhibit high absorption capacity owing to their large leaves; however, worst air conditions normally occur in winter seasons [21], [22]. Researchers also agreed that the "mixed species structures" exhibit the highest air purification capacity [23]. The vegetation "density" and "openness" are also important factors; a single plant filters less amount of dust than groups or rows of vegetation [24]; however, some studies have reported that thick vegetation possibly causes air turbulence, whereas a thinner cover is possibly better in allowing air movement and filtering [24]. Other urban infrastructures (e.g., water and open sealing spaces) are normally neglected [25] and are widely recognized to exhibit much less capacity.

\subsubsection{Microclimate regulation}

Literature indicated that "microclimate regulation" is normally combined with greenhouse gas and steam. Moreover, only "temperature reduction" is concerned, especially in the context of urban heating. First, the vegetation feature of "biotype" mostly focuses, and although "tree" is supposed to exhibit higher capacity for temperature reducing than "herb", a few studies have reported that "herb" could reduce higher amount for advantages in "openness" [26]. Some studies have also reported that "mixed biotypes" containing both "tree" and "herb" showed the highest capacity for temperature reduction [27] followed by the biotypes containing either "tree" or "herb" vegetation only, which exhibit comparable capacities. The "leaf size" factor is also widely investigated because of its direct role in sunlight shading and has always been investigated along with other biophysical features, e.g., leaf area index (LAI) and average angles between foliage and horizon [28], [29]. Other structural factors, e.g. "density," "height," and "age," are normally indirectly investigated.

\subsubsection{Noise reduction}

The "noise" in cities is normally the "traffic noise," and the most crucial factor is "the distance to noise source" [32]. Thus, the potential factors including "ground character," "habitat size," and "denseness/thickness," as well as their interactions. When these factors are combined with "biotype," the "tree" and "shrub" are considered to exhibit greater noise reduction capacity than "herb" [15]. However, some investigations found the highest noise reduction capacity in multi-species constructions [33]. Moreover, "habitat sizes" influence noise reduction, although this factor is normally associated with "noise source distance" indicators. The "denseness" and "thickness" of UGI exhibit the highest influence on noise reduction; however, quantitative results on these factors are usually uncertain. For instance, some studies have reported that a $5 \mathrm{~m}$ wide dense shrubbery reduces noise levels by at least $2 \mathrm{~dB}(\mathrm{~A})$, and a $50 \mathrm{~m}$ side plantation can lower noise levels by 3-6 dB (A) [21]. Other studies have shown that to achieve high absorption of $5 \mathrm{~dB}(\mathrm{~A})$ or better, the width of vegetation barrier must be at least $1.5 \mathrm{~m}$ thick [34]. However, the capacity of vegetation to reduce noise is limited compared with that of modern brick works [35], e.g., a typical wall can easily reduce noise by $10-15 \mathrm{~dB}(\mathrm{~A})$ immediately behind it [21]. The noise reduction capacity of other materials has also been reported, e.g., water does not contribute to noise reduction because sounds propagate to long distances through water [21].

\subsubsection{CSS}

With the increasing atmospheric $\mathrm{CO}_{2}$ concentration caused by anthropogenic activities, the CSS services provided by UGI are also concerned [36]. For the CSS service of UGI can be classified into "carbon sequestration from the atmosphere" and "carbon loss into the atmosphere," and "biomass accumulation" [37], as a result, the "net primary production" and its related factors are frequently analyzed [38]. Moreover, the "leaf size" structure is mostly analyzed with "LAI" in determining the direct influences of CSS to biomass accumulation in both photosynthesis and respiration. Other structural factors, e.g., "density" and "coverage," were also analyzed [39]. The "biotype" was also analyzed, wherein the "tree" is normally found to exhibit higher capacity than the "shrub" 
and "herb." However, other studies have revealed that the highest capacity is shown by multi-biotypes, especially mature forests that include "tree-shrub-herb" [40].

\subsubsection{Rainwater retention}

Urban flood is another frequently discussed issue in modern cities, especially in the context of global precipitation imbalances. UGI performs a crucial role because it normally receives high amount of rainfall [41]. Considering the mechanism of physical soil permeation, bio-absorption, and water release through evapotranspiration [21], the capacity of vegetation for water retention is significantly higher than that of unsealed soil [41]. "Bio-type" is also important particularly when involving the "tree," which exhibits high potential in water absorption and evapotranspiration [21]. Asphalted infrastructures show negative effects in water retention because high proportion of rainfall is easily turned into surface run-off, which increases the risks of urban flooding [41]. Moreover, "vegetation density" is also the crucial indicator of water retention.

\subsection{Final chosen of UGI structure indicators}

We defined herein "UGI structure indicators" as features that are observable and classifiable. As presented above, the indicators such as "leaf size," "biotype," "thickness," "density," and "height" are frequently reported in literature (Table 1). Thus, these crucial indicators are considered as elementary factors.

Table 1. List of the reported crucial UGI structure indicators in specific UES studies.

\begin{tabular}{|c|c|c|c|c|c|c|}
\hline Regulation UES & Biotype & Thickness & Density & Leaf size & Height & Age \\
\hline Air purification & $\mathrm{X}$ & $\mathrm{X}$ & $\mathrm{X}$ & $\mathrm{X}$ & $\mathrm{X}$ & \\
\hline Microclimate regulation & $\mathrm{X}$ & & $\mathrm{X}$ & $\mathrm{X}$ & $\mathrm{X}$ & $\mathrm{X}$ \\
\hline Noise reduction & $\mathrm{X}$ & $\mathrm{X}$ & $\mathrm{X}$ & & & \\
\hline Carbon sequestration and storage (CSS) & $\mathrm{X}$ & $\mathrm{X}$ & $\mathrm{X}$ & $\mathrm{X}$ & & $\mathrm{X}$ \\
\hline Rainwater retention & $\mathrm{X}$ & & $\mathrm{X}$ & & & \\
\hline
\end{tabular}

Table 2. UGI structural models including their crucial indicators.

\begin{tabular}{|c|c|c|c|c|c|c|}
\hline UGI Structural Models & Biotype & Thickness & Density & Leaf Size & Height & Age \\
\hline \multirow{3}{*}{ Forest A } & Tree & & $50 \% \sim 100 \%$ & $>10 \mathrm{~cm}^{2}$ & $>4 \mathrm{~m}$ & $>5 \mathrm{yr}$. \\
\hline & Shrub & $>50 \mathrm{~m}^{2}$ & $25 \%-75 \%$ & - & $0.5-4 \mathrm{~m}$ & - \\
\hline & Herb & & $0 \%-50 \%$ & - & $<0.5 \mathrm{~m}$ & - \\
\hline Forest B & Tree & $>50 \mathrm{~m}^{2}$ & $100 \%$ & $>10 \mathrm{~cm}^{2}$ & $>4 \mathrm{~m}$ & $>5 \mathrm{yr}$. \\
\hline \multirow{2}{*}{ Forest C } & Tree & $>50 \mathrm{~m}^{2}$ & $50 \%-100 \%$ & $>10 \mathrm{~cm}^{2}$ & $>4 \mathrm{~m}$ & $>5 \mathrm{yr}$. \\
\hline & Shrub/Herb & $>50 \mathrm{~m}^{2}$ & $0 \%-50 \%$ & - & $<0.5 \mathrm{~m}$ & - \\
\hline \multirow{2}{*}{ Shrub D } & Shrub & $>10 \mathrm{~m}^{2}$ & $50 \%-100 \%$ & - & $0.5-4 \mathrm{~m}$ & - \\
\hline & Herb & & $0 \%-50 \%$ & - & $<0.5 \mathrm{~m}$ & $>3 \mathrm{yr}$. \\
\hline Shrub E & Shrub & $>10 \mathrm{~m}^{2}$ & $50 \%-100 \%$ & - & $<0.5 \mathrm{~m}$ & $>1 \mathrm{yr}$. \\
\hline Lawn F & Herb & $>50 \mathrm{~m}^{2}$ & $100 \%$ & - & $<0.5 \mathrm{~m}$ & - \\
\hline Water G & - & $>10 \mathrm{~m}^{2}$ & - & - & - & - \\
\hline Sealing $\mathrm{H}$ & - & $>10 \mathrm{~m}^{2}$ & - & - & - & - \\
\hline Architecture I & - & $>10 \mathrm{~m}^{2}$ & - & - & - & - \\
\hline
\end{tabular}

* "_-" means no requirements.

\subsection{Construction of UGI structural models}

Natural and artificial structures are both analyzed in UES assessment [17], [42] giving emphasis on specific UGI characterizations, such as type and size [14]. As a result, the vegetation biotypes "tree," "shrub," and "herb" are selected and so do other materials, such as "water". For the normal conditions in UGI environment, "sealing" and "architecture" were also included [43]. In addition, the detailed classification of biotype compositions is our focus because of their multi-structural effects (Table 2). Vegetation bio-types are normally labeled with various names, such as "tree," "shrub," "shrubbery," "bush," "grass," "herb," and "hedge," although most of these terms are synonymous. A clear definition of "tree," "shrub," and "herb" is needed; thus, we used the concept of "morphology" in this study. Basing on literature review, we speculate that "herb" is easily recognizable; however, most of the confusion happens in classifying "tree" and "shrub." Some researchers classified certain species as "trees" and others as "shrubs." Moreover, some used DBH (diameter at breast height) as basis of classification, wherein a "tree" is higher than or equal to, whereas "shrub" is shorter than $2.54 \mathrm{~cm}$ (1 in) [44]. Herein, our basis of classification is "height" for its roles in environment [16]. All of these indicators can be measured quantitatively; in addition, considering their varying roles and complex interactions, nine UGI structural models were reported in academic literature [16] (Table 2).

\subsection{Construction of UGI assessment system}

With the aim of conducting UES assessment, an assessment system is constructed based on UGI structural models and their efforts. Herein, the five UES are listed and quantitatively represented by positive, negative, and 
neutral scores. The literature and experts indicate that the scores from " -5 " to " 5 " represent the most negative and most positive efforts (Table 3).

\subsubsection{Air purification}

Similar to that in previous discussion and classification, our result showed that "vegetation with tree and multibiotypes" ("forest A") showed the highest score followed by "forest B" and "forest C," which both exhibited relatively high scores owing to the relatively high services provided by the "tree" biotype. "Shrub D," "shrub E," and "lawn F" also showed positive but relatively low scores.

"Water G" showed slight but certain effects because some air pollutants (e.g., $\mathrm{SO}_{2}$ ) may dissolve in water. "Sealing H" and "architecture I" are considered with no effects for no reports are available.

\subsubsection{Microclimate regulation}

Among all the structural models, "water G" showed the highest service because it exhibits the highest "specific heat capacity." Second in the ranking is "vegetation structures containing both tree and herb biotypes," including "forest $\mathrm{A}$ " and "forest $\mathrm{C}$ ". Third in the ranking is the single biotype structure of "forest B" and "lawn F." In addition, shrub vegetation ("shrub C" and "shrub D") also provided some benefits. The asphalted lands were also investigated; however, they received negative scores. Related studies showed that the asphalted land would increase the surface temperature by up to $4.7^{\circ} \mathrm{C}$ and the air temperature by up to $3.2{ }^{\circ} \mathrm{C}$ [16]. For the temperature, increasing efforts showed through figures are much significant. The lowest " -5 " score is given to both structure models of "sealing H" and "architecture I." These rankings are consistent with the findings of other scholars [14].

\subsubsection{Noise reduction}

"Architecture I" showed the highest score because of its huge effects in sound isolation. The "denseness" and "thickness" are the most important features of those vegetation structural models. The second highest value was assigned to "forest A" (tree-shrub - herb) owing to its thickness followed by "shrub D." "forest C" and "forest B" were third in the ranking followed by "shrub E." Considering the similarity in "openness", "water G," "sealing H," and "lawn F" are distributed with neutral grades.

\subsubsection{CSS}

With its crucial roles in biotype and age, "forest A" showed the highest score. Other structural models related to "tree" ("forest B" and "forest C") also showed relatively high scores. The other vegetation structures showed relatively low scores. "Water G" received a positive score owing to its functions in $\mathrm{CO}_{2}$ dissolution, whereas the structural models "sealing" and "architecture" received neutral scores resulting from the absence of related studies.

\subsubsection{Rainwater retention}

Although "water G" land use would exert negative effects when the amount of water exceeds the capacity of the soil, this model still received the highest score considering the normally low horizontal plane and relatively large water content. The services provided by the vegetation structural models showed higher scores than those of the artificial structures. Moreover, "denseness" and "soil-water retention" capacities were analyzed, as a result, "forest A" showed the second highest rank followed by "forest C." Following in the ranking are "forest B," "shrub D," "shrub E," and "lawn F," which showed relatively lower positive scores. Furthermore, "sealing H" and "architecture I" exerted negative effects because the asphalt coverage could increase the risk of urban flooding.

Table 3. Construction of UES assessment system with quantitative grades.

\begin{tabular}{cccccc}
\hline & $\begin{array}{c}\text { Air } \\
\text { Purification }\end{array}$ & $\begin{array}{c}\text { Microclimate } \\
\text { Regulation }\end{array}$ & $\begin{array}{c}\text { Noise } \\
\text { Reduction }\end{array}$ & $\begin{array}{c}\text { Carbon Sequestration and } \\
\text { Storage (CSS) }\end{array}$ & $\begin{array}{c}\text { Rainwater } \\
\text { Retention }\end{array}$ \\
\hline Forest A & 5 & 4 & 4 & 5 & 4 \\
Forest B & 3 & 2 & 2 & 3 & 2 \\
Forest C & 4 & 3 & 2 & 4 & 3 \\
Shrub D & 2 & 1 & 3 & 2 & 2 \\
Shrub E & 1 & 1 & 1 & 2 & 2 \\
Lawn F & 1 & 2 & $0 / ?$ & 1 & 1 \\
Water G & 1 & 5 & $0 / ?$ & $0 / ?$ & 5 \\
Sealing H & $0 / ?$ & -5 & $0 / ?$ & $0 / ?$ & -5 \\
Architecture I & $0 / ?$ & -5 & 5 & & -5 \\
\hline
\end{tabular}




\section{Results}

\subsection{Site introduction}

Being the largest city in China, Shanghai is a typical city exhibiting rapid urbanization and environmental deterioration. The city has paid attention on constructing UGIs particularly for the past 30 years, but the green cover in Shanghai remains limited, especially when compared with other megacities worldwide. The land area used for UGI is less than $10 \%$ in center Shanghai, which supports a huge population of over 20 million, as well as intense human activities [45]. Thus, achieving the maximum UES benefit from the current UGI and related assessment works are strongly needed.

Our field survey in the central regions of Shanghai showed that the most dweller-interacted UGI are the urban parks. Being influenced by Western culture since the late 19th century, Shanghai is the first city in China that constructed modern parks. We chose two typical parks of similar size but of different ages for this case study; these parks are the Fuxing Park (built in 1909 and with a total land area of $7.3 \mathrm{ha}$ ) and the Lujiazui Central Green Space (built in 1997 and with a total land area of 10 ha).

\subsection{Methodology implementation quantitative results}

Two research sites in Shanghai were selected for the case studies, and our UES assessment methodology was adjusted and implemented in combination with local conditions. Basing from the results and related discussions, we identified and analysed the loopholes of our methodology and related feedback.

Using the actual UGI structure models during the field survey conducted from September to December in 2014, we identified all the land uses in those two parks; in addition, data on land size was collected using GIS mapping. The whole assessment methodology, combined with the previous quantitative assessment tools, could then be implemented, and each UES (air purification, microclimate, noise reduction, $\mathrm{CSS}$, and rainwater retention) in those two parks could be compared.

As it shown in Figure 1, the effects exerted by the vegetation in Fuxing Park and Lujiazui Central Green Space showed positive scores in all of the five selected UES sorts. The services of "microclimate regulation" and "rainwater retention" were lower than those of the three other models, and nearly all UES sorts in Fuxing Park were higher in this park than in Lujiazui Central Green Space, except for "microclimate regulation" service, which was slightly lower in the former (with score gap of 0.08 ).

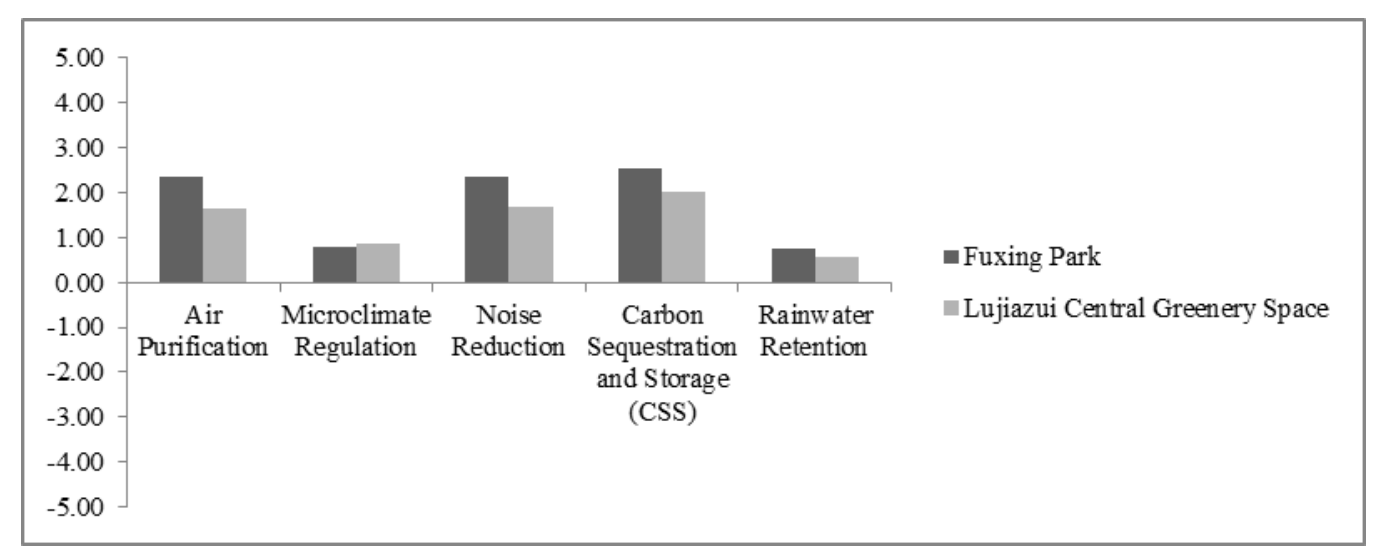

Figure 1. Quantitative comparisons between Fuxing Park and Lujiazui Central Green Space.

\section{Discussion}

\subsection{Case study discussion}

For the significant differences in UGI structure, quantitative values were also different in those two parks. The structures of "Forest B" and "Lawn F" require further discussions. Compared with only $10 \%$ coverage of "Lawn F" in Fuxing Park, the greater coverage (35\%) of "Lawn F" in Lujiazui Central Green Space is the main reason for higher values in "microclimate regulation." Other UES values are all higher because many highly graded UGI structures (e.g., "Forest B") are present in Fuxing Park. But for there are no significant advantages, the UES advantages are not large (gaps within 0.19-0.71).
The discussion presented above shows that regulation UES involves strong interaction with "biodiversity" and "cultural services". Literature review and expert knowledge have revealed that UGI structures with multibiotypes (high biodiversity) normally render great effects. And also, cultural activities would affect UGI planning and management by various demands (i.e. Taiji is more preferred in Fuxing Park and music concerts are more preferred in Lujiazui Central Green Spaces). This phenomenon is evident in Shanghai owing to its greater number of "sealing H" and "architecture I" compared with Europe, and the direct effects of these factors showed relatively low scores. "Water G" land use can be suggested for UGI planning and management in Shanghai, although a balanced utilization of other structures must be considered because of limited land resource. 


\subsection{Methodology discussion}

Basing on the results of our case study, we discuss herein the feedback on this modelling methodology. First, this modelling methodology is constructed based on scientific psychological principles in modelling construction, and it could be implied with regulation UES assessment and quantitative results. Second, this methodology also highly concerns on place-based field survey, and thus open sources to reality situations, and even possibly push certain limitations when implemented in large scales, (e.g., regional and national levels). Third, the methodology brought new insight into the interaction among "regulation UES," "biodiversity," and "cultural UES," and this relationship could open new insights to further investigations with related research works. In addition, with the openness of modelling and related quantitative assessment, the methodology is advantaged for it can be further improved with further academic literatures and developing expert knowledge. When comparing with other model researches in the world, we find out the different structures are normally strongly interacted with each other, and this should be improved in the further researches [46]. And under the future concerns in multifunctionality demands, how could scientific models and suggestions being implemented into actual planning works also need further discussions, and related feedbacks especially to spatial solutions are widely recognized as further necessaries [47].

\section{Conclusion}

This study focused on physiological mechanisms, and UES assessment modelling methodology based on UGI structural indicators is constructed. Basing on the reported indicators, which demonstrated the effects of UGI structures in regulation UES, we designed nine UGI structural models, and built assessment system with quantitative values. This modelling methodology is involved in specific regulation UES, including "air purification," "microclimate regulation," "noise reduction," "CSS," and "rainwater retention," and was implemented in a case study in two urban parks in Shanghai. With the feedback to our methodology and the analysis based on the obtained quantitative results, this assessment methodology should be suitable for patchlevel studies and can be implied to those with limited capacity for collecting sufficient primary data.

\section{Acknowledgments}

I express my sincere gratitude to Professor Jürgen Breuste of Salzburg University for his helps in expert knowledge, Professor Li Junxiang of East China Normal University and his team for their support in field survey and to Ms. Elieen Saupe of Technology University of Dresden for the GIS mapping.

\section{References}

1. Abou, R. Y., Leuschner, C., Barus, H., Tjoa, A., and Hertel, D. (2016) Cacao cultivation under diverse shade tree cover allows high carbon storage and sequestration without yield losses. Plos One., 11(2): 1-22.

2. Behling, R., Bochow, M., Foerster, S., Roessner, S., and Kaufmann, H. (2015) Automated GIS-based derivation of urban ecological indicators using hyperspectral remote sensing and height information. Ecological Indicators., 48(48): 218 234.

3. Bolund, P., and Hunhammer, S. (1999) Ecosystem services in urban areas. Ecological Economics., 29: 293-301.

4. Castán Broto, V., and Bulkeley, H. (2013) A survey of urban climate change experiments in 100 cities. Global Environmental Change., 23(1): 92102.

5. Cavan, G., Lindley, S., Jalayer, F., Yeshitela, K., Pauleit, S., Renner, F., Gill, S., Capuano, P., Nebebe, A., Woldegerima, T., Kibassa, D., and Shemdoe, R. (2014) Urban morphological determinants of temperature regulating ecosystem services in two African cities. Ecological Indicators., 42: 43-57.

6. Chen, X., Wang, L., Tong, L., Sun, S., Yue, X., Yin, S., and Zheng, L. (2014) Mode selection of China's urban heating and its potential for reducing energy consumption and $\mathrm{CO} 2$ emission. Energy Policy., 67: 756-764.

7. Chen, Y., Zhou, H., Zhang, H., Du, G., and Zhou, J. (2015) Urban flood risk warning under rapid urbanization. Environmental Research., 139: 3-10.

8. Cheshmehzangi, A., and Butters, C. (2017) Chinese urban residential blocks: Towards improved environmental and living qualities. URBAN DESIGN International., 22(3): 219-235.

9. D’Odorico, P., He, Y., Collins, S., De Wekker, S. F. J., Engel, V., and Fuentes, J. D. (2013) Vegetation-microclimate feedbacks in woodlandgrassland ecotones. Global Ecology \& Biogeography., 22(4): 364-379.

10. Ebadi, L., and Shafri, H. Z. M. (2015) A stable and accurate wavelet-based method for noise reduction from hyperspectral vegetation spectrum. Earth Science Informatics., 8(2): 411-425.

11. Elmqvist, T., Setälä, H., Handel, S., van der Ploeg, S., Aronson, J., Blignaut, J., Gómez-Baggethun, E., Nowak, D., Kronenberg, J., and de Groot, R. (2015) Benefits of restoring ecosystem services in urban areas. Current Opinion in Environmental Sustainability., 14: 101-108.

12. Giedych, R., and Maksymiuk, G. (2017) Specific features of parks and their impact on regulation and cultural ecosystem services provision in Warsaw, Poland. Sustainability (Switzerland)., 9(5): 1-18. 
13. Gill, S. R., Pop, M., DeBoy, R. T., Eckburg, P. B., Turnbaugh, P. J., Samuel, B. S., Gordon, J. I., Relman, D. A., Fraser-Liggett, C. M., and Nelson, K. E. (2006) Metagenomic analysis of the human distal gut microbiome. Science., 312(5778): 13551359.

14. Haase, D., Larondelle, N., Andersson, E., Artmann, M., Borgström, S., Breuste, J., Gomez-Baggethun, E., Gren, Å., Hamstead, Z., Hansen, R., Kabisch, N., Kremer, P., Langemeyer, J., Rall, E. L., McPhearson, T., Pauleit, S., Qureshi, S., Schwarz, N., Voigt, A., Wurster, D., and Elmqvist, T. (2014) A quantitative review of urban ecosystem service assessments: Concepts, models, and implementation. AMBIO., 43(4): 413-433.

15. Hansen, R., and Pauleit, S. (2014) From multifunctionality to multiple ecosystem services? A conceptual framework for multifunctionality in green infrastructure planning for Urban Areas. Ambio., 43(4): 516-529.

16. Jang, H. S., Kim, H. J., and Jin, Y. J. (2015) Scalemodel method for measuring noise reduction in residential buildings by vegetation. Building \& Environment., 86: 81-88.

17. Janhäll, S. (2015) Review on urban vegetation and particle air pollution - Deposition and dispersion. Atmospheric Environment., 105: 130-137.

18. Jim, C. Y., and Shan, X. (2013) Socioeconomic effect on perception of urban green spaces in Guangzhou, China. Cities., 31: 123-131.

19. Kaczorowska, A., and Architecture, F. (2014) Ecosystem Services and Urban Resilience - Case of Stockholm. 1-9.

20. Kalansuriya, C. M., Pannila, A. S., and Sonnadara, D. U. J. (2009) Effect of roadside vegetation on the reduction of traffic noise levels. Proceedings of the Technical Sessions. Institute of Physics - Sri Lanka., 25: 1-6.

21. De Kauwe, M. G., Medlyn, B. E., Zaehle, S., Walker, A. P., Dietze, M. C., Wang, Y. P., Luo, Y., Jain, A. K., Elmasri, B., and Hickler, T. (2014) Where does the carbon go? A model-data intercomparison of vegetation carbonallocation and turnover processes at two temperate forest free-air $\mathrm{CO} 2$ enrichmentsites. New Phytologist., 203(3): 883-899.

22. Lehmann, I., Mathey, J., Rößler, S., Bräuer, A., and Goldberg, V. (2014) Urban vegetation structure types as a methodological approach for identifying ecosystem services - Application to the analysis of micro-climatic effects. Ecological Indicators., 42: 58-72.

23. Liu, B., Zhou, Y., and Li, Y. (2015) The analysis of the accumulation of four kinds of atmospheric pollution elements in fifteen kinds of landscape plant leaves. Journal of Animal \& Plant Sciences., 25(3): 213-219.

24. Madureira, H., and Andresen, T. (2014) Planning for multifunctional urban green infrastructures:
Promises and challenges. Urban Design International., 19(1): 38-49.

25. Martilli, A. (2014) An idealized study of city structure, urban climate, energy consumption, and air quality. Urban Climate., 10: 430-446.

26. Mnes, O. O. A. (2014) Review of the role of plant in carbondioxide sequestration globally using chlorophy II or leaf index. Journal of Environment and Earth Science., 4(22): 22-30.

27. Nowak, D. J., Crane, D. E., Stevens, J. C., Hoehn, R. E., Walton, J. T., and Bond, J. (2008) A groundbased method of assessing urban forest structure and ecosystem services. Aboriculture \& Urban Forestry., 34(6): 347-358.

28. Palace, M. W., Sullivan, F. B., Ducey, M. J., Treuhaft, R. N., Herrick, C., Shimbo, J. Z., and Mota-E-Silva, J. (2015) Estimating forest structure in a tropical forest using field measurements, a synthetic model and discrete return lidar data. Remote Sensing of Environment., 161: 1-11.

29. Pascal, M., Corso, M., Chanel, O., Declercq, C., Badaloni, C., Cesaroni, G., Henschel, S., Meister, K., Haluza, D., Martin-olmedo, P., and Medina, S. (2013) Assessing the public health impacts of urban air pollution in 25 European cities : Results of the Aphekom project. Science of the Total Environment., 449(2): 390-400.

30. Qin, Z., Li, Z., Cheng, F., Chen, J., and Liang, B. (2014) Influence of canopy structural characteristics on cooling and humidifying effects of Populus tomentosa community on calm sunny summer days. Landscape and Urban Planning., 127 75-82.

31. Sett, R. (2017) Responses in plants exposed to dust pollution. 1(2): 53-56.

32. Shanghai Municipal Statistic Bureau, and Survey Office of the National Bureau of Statistics in Shanghai. (2015). Shanghai statistical yearbook 2014. China Statistics Press, Shanghai.

33. Shiflett, S., Shi, S. A., Liang, L. L., Crum, S. M., Feyisa, G. L., Wang, J., and Jenerette, G. D. (2017) Variation in the urban vegetation, surface temperature, air temperature nexus. Science of the Total Environment., 579: 495-505.

34. Skelhorn, C., Lindley, S., and Levermore, G. (2014) The impact of vegetation types on air and surface temperatures in a temperate city: A fine scale assessment in Manchester, UK. Landscape and Urban Planning., 121: 129-140.

35. Triguero-Mas, M., Dadvand, P., Cirach, M., Martínez, D., Medina, A., Mompart, A., Basagaña, X., Gražulevičienè, R., and Nieuwenhuijsen, M. J. (2015) Natural outdoor environments and mental and physical health: Relationships and mechanisms. Environment International., 77: 3541. 
36. Vidrih, B., and Medved, S. (2013) Multiparametric model of urban park cooling island. Urban Forestry \& Urban Greening., 12(2): 220-229.

37. Wang, Y., Bakker, F., de Groot, R., and Wörtche, H. (2014) Effect of ecosystem services provided by urban green infrastructure on indoor environment: A literature review. Building and Environment., 77: 88-100.

38. Weber, N., Haase, D., and Franck, U. (2014) Assessing modelled outdoor traffic-induced noise and air pollution around urban structures using the concept of landscape metrics. Landscape \& Urban Planning., 125(6): 105-116.

39. Wei, J., Qian, J., Tao, Y., Hu, F., and Ou, W. (2018) Evaluating spatial priority of urban green infrastructure for urban sustainability in areas of rapid urbanization: A case study of Pukou in China. Sustainability (Switzerland)., 10(2).

40. Wu, J., Wei-Ning Xiang, and Zhao, J. (2014) Urban ecology in China: Historical developments and future directions. Landscape and Urban Planning., 125: 222-233.

41. Xie, H. Y., Chang-Wen, M. A., Sun, Z. G., Gao, G. L., Bing, N. C., Tian, Z., Zhu, L. P., Wang, L. L., Yang, D. D., and Chen, S. W. (2014) Mixed crystal structures of nano tio_2 by flame chemical vapor deposition process and applications in photocatalytic gas purifications. Journal of Shanghai Second Polytechnic University.

42. Xu, X. G., Cui, C. W., Xu, L. F., and Ma, L. Y. (2013) Method study on relative assessment for ecosystem service: A case of green space in Beijing, China. Environmental Earth Sciences., 68(7): 1913-1924.

43. Xue, F., Gou, Z., and Lau, S. (2017) The green open space development model and associated use behaviors in dense urban settings: Lessons from Hong Kong and Singapore. Urban Design International., 22(4): 287-302.

44. Yang, L., Zhang, L., Li, Y., and Wu, S. (2015) Water-related ecosystem services provided by urban green space: A case study in Yixing City (China). Landscape and Urban Planning., 136: 4051.

45. Yusuf, H. M., Treydte, A. C., and Sauerborn, J. (2015) Managing semi-arid rangelands for carbon storage: Grazing and woody encroachment effects on soil carbon and nitrogen. Plos One., 10(10).

46. Zhang, Z., Lv, Y., and Pan, H. (2013) Cooling and humidifying effect of plant communities in subtropical urban parks. Urban Forestry \& Urban Greening., 12(3): 323-329.

47. Zou, B., Xu, S., Sternberg, T., and Fang, X. (2016) Effect of land use and cover change on air quality in urban sprawl. Sustainability., 8(7): 677-690. 